Original Article

\title{
Effects of Pelvic Belt on Hip Extensor Muscle EMG Activity during Prone Hip Extension in Females with Chronic Low Back Pain
}

\author{
JAE-SEOP OH, PT, $\mathrm{PhD}^{1)}$ \\ 1) Department of Physical Therapy, College of Biomedical Science and Engineering, Inje University: \\ 607 Obang-dong, Gimhae-si, Gyeongsangnam-do 621-749, Republic of Korea
}

\begin{abstract}
Purpose] This study assessed the effects of a pelvic belt (PB) on the electromyography (EMG) activity of the elector spinae (ES), gluteus maximus (GM), and biceps femoris (BF) in females with chronic low back pain (CLBP) during prone hip extension (PHE). [Subjects] Twenty female with CLBP were recruited. Surface EMG data were collected from the ES, GM, and BF muscles during a PHE task. [Results] The EMG activity in the ES bilaterally, and the right GM decreased significantly when a PB was applied compared with when a PB was not applied. [Conclusion] This suggests that a PB is effective for altering the activation pattern of the hip extensor muscles in females with CLBP during PHE.
\end{abstract}

Key words: Chronic low back pain, Pelvic belt, Prone hip extension

(This article was submitted Dec. 13, 2013, and was accepted Jan. 8, 2014)

\section{INTRODUCTION}

Prone hip extension (PHE) is used to test lumbopelvic movement and as a therapeutic exercise in patients with low back pain to strengthen the trunk and hip muscles ${ }^{1)}$. When performing this exercise, the lumbopelvic region should be maintained in a neutral position without rotating the lumbar spine and pelvis region. Many researchers have reported that the increased elector spinae (ES), gluteus maximus (GM), and biceps femoris (BF) muscles during various tasks are due to imbalance of the lumbopelvic muscles in lumbopelvic dysfunction (Arab et al., 2011)2). Researchers have suggested that the pelvic belt (PB) is effective at stabilizing the pelvic articulations, allowing exercises addressing coordination and stabilization ${ }^{3)}$. The PB has been shown to relieve pain and facilitate neuromuscular performance during rehabilitation exercises in patients with lumbopelvic problems ${ }^{4)}$. Hu et al. ${ }^{5}$ reported that use of a PB during ASLR results in improved ASLR performance and reduced abdominal muscle activation. Although many clinicians apply a PB to prevent substitution movement, no study has examined its effect on the activation pattern of the hip extensor muscles in a prone position such as PHE in females with chronic low back pain (CLBP). Therefore, this study investigated the effects of a PB on hip extensor muscles activation patterns during PHE in females with CLBP.

Corresponding author. Jae-Seop Oh (E-mail: ysrehab@inje. ac.kr)

(C2014 The Society of Physical Therapy Science. Published by IPEC Inc. This is an open-access article distributed under the terms of the Creative Commons Attribution Non-Commercial No Derivatives (by-ncnd) License $<$ http://creativecommons.org/licenses/by-nc-nd/3.0/>.

\section{SUBJECTS AND METHODS}

Twenty female with CLBP aged 45 to 56 years volunteered for this study. The inclusion criteria were CLBP for more than 3 months and the willingness and ability to participate in the task safely. Their mean age was $49.73 \pm$ 6.62 years, and their mean height and weight were 152.33 $\pm 5.77 \mathrm{~cm}$ and $51.85 \pm 8.23 \mathrm{~kg}$, respectively. All subjects read and signed an informed consent form approved by the Inje University Ethics Committee for Human Investigations prior to participation.

The EMG data were recorded and analyzed using a Delsys Trigno Wireless EMG system (Delsys, Boston, MA, USA). EMG data were collected bilaterally from the ES ( $2 \mathrm{~cm}$ lateral to the spinous process of the L1 level and aligned parallel to the spine), GM (half the distance between the greater trochanter and second sacral vertebra and at an oblique angle at or slightly above the level of the trochanter), and BF ( $2 \mathrm{~cm}$ from the lateral border of the thigh and two-thirds the distance between the trochanter and back of the knee) muscles (Criswell, 2010). The signals were amplified and band-pass filtered $(20-450 \mathrm{~Hz})$ before being recorded digitally at 2,000 samples/s, and then the root mean square (RMS) was calculated. Maximum isometric contractions were performed against manual resistance for all muscles (Kendall, 2005) ${ }^{6}$. Each maximum isometric contraction maneuver was performed twice for $5 \mathrm{~s}$, and the average muscle activity for the middle $3 \mathrm{~s}$ of the two trials was used for normalization. The PB (SI-LOC, OPTP, Canada) was applied below the anterior superior iliac spine ${ }^{7)}$ in the subjects, and the strap was fastened firmly to the belt. The tightness was adjusted by a physiotherapist with experience in dealing with females suffering from CLBP.

The individuals were asked to lie prone with their arms 
at their sides and head in the mid-line. An adjustable bar was placed over the experimental table in alignment with the back of knee so that the popliteal region contacted the bar during the hip extension task. A target bar was set at $10^{\circ}$ to provide tactual feedback. The individuals were told to extend their dominant leg from neutral to about $10^{\circ}$ while keeping the knee extended. All individuals reported that they were right-leg dominant. The subjects were asked to perform hip extension and maintain the position for $5 \mathrm{~s}$. The PHE tasks were performed with and without a PB in randomized order. A 1-min rest was allowed between contractions. The activity of the hip extensor muscles was compared between with and without a PB by paired t-tests. The statistical analyses were performed using SPSS (ver. 17.0; SPSS, Chicago, IL, USA). P-values $<0.05$ were considered to indicate statistical significance.

\section{RESULTS}

The EMG signal amplitude (\%MVIC) decreased significantly in the left $\mathrm{ES}$ (mean $\pm \mathrm{SD}, 39.79 \pm 7.08$ compared with $49.87 \pm 9.69$ ), right ES (mean $\pm \mathrm{SD}, 40.16 \pm 12.13$ compared with $47.41 \pm 12.09$ ), and right GM (mean $\pm \mathrm{SD}, 24.18$ \pm 7.59 compared with $30.31 \pm 14.22$ ) with a PB compared with the without a PB condition in the females with CLBP $(p<0.05)$. The EMG signal amplitude did not differ in the bilateral BF and left GM between the conditions ( $p>0.05)$.

\section{DISCUSSION}

This study examined whether a PB affects the ES, GM, and $\mathrm{BF}$ muscle activation patterns during PHE in females with and without CLBP.

We observed reduced left and right ES and right GM activity with a PB in females with CLBP compared without a PB during PHE. To improve motor control of the lumbopelvic region, many researchers have recommended lumbar stabilization methods ${ }^{8)}$. Lumbar stabilization can be achieved by either isometric action of the abdominal muscles or external pelvic compression. If lumbar stabilization exercises are inappropriate, Pel et al. ${ }^{9)}$ recommended applying a PB. Park et al. ${ }^{10)}$ and Takasaki et al. ${ }^{11)}$ accept that a PB can improve neuromuscular control and prevent unwanted substitution movement during hip joint movement. We found that use of a PB reduced the left and right ES and right GM activity, which could be due to decreased unwanted substitution strategies, such as anterior pelvic tilt or excessive lumbar extension during PHE in females with CLBP. Therefore, use of a PB might have improved the compensatory movement in a neutral position and provided proper load transfer to the lumbar in females with CLBP during PHE.

This study had several limitations. First, we did not consider kinematic factors when measuring the effect of the PB during the PHE. Kinematic data could provide more detailed information on the hip extension substitution movement. Second, we did not quantify the PB tension. Finally, our study measured the EMG activity of the trunk and hip, but this is insufficient to represent muscle force directly. Further studies are needed to assess the effects of $\mathrm{PB}$ on the lower extremity force in females with CLBP during PHE.

\section{REFERENCES}

1) Oh JS, Cynn HS, Won JH, et al.: Effects of performing an abdominal drawing-in maneuver during prone hip extension exercises on hip and back extensor muscle activity and amount of anterior pelvic tilt. J Orthop Sports Phys Ther, 2007, 37: 320-324. [Medline] [CrossRef]

2) Arab AM, Ghamkhar L, Emami M, et al: Altered muscular activation during prone hip extension in women with and without low back pain. Chiropr Man Therap, 2011, 19: 18. [Medline] [CrossRef]

3) Vleeming A, Buyruk HM, Stoeckaright R, et al.: An integrated therapy for peripartum pelvic instability: a study of the biomechanical effects of pelvic belts. Am J Obstet Gynecol, 1992, 166: 1243-1247. [Medline] [CrossRef]

4) Lee DG: The Pelvic Girdle, 3rd ed. Edinburgh: Churchill Livingstone 2004

5) $\mathrm{Hu} \mathrm{H}$, Meijer OG, van Dieën JH, et al.: Muscle activity during the active straight leg raise (ASLR), and the effects of a pelvic belt on the ASLR and on treadmill walking. J Biomech, 2010, 43: 532-539. [Medline] [CrossRef]

6) Kendall FP, McCreary EK, Provance PG, et al.: Muscles: Testing and Function with Posture and Pain, 5th ed. Baltimore: Lippincott Williams \& Wilkins, 2005.

7) Damen L, Spoor CW, Snijders CJ, et al.: Does a pelvic belt influence sacroiliac joint laxity? Clin Biomech (Bristol, Avon), 2002, 17: 495-498. [Medline] [CrossRef]

8) Arumugam A, Milosavljevic S, Woodley S, et al.: Effects of external pelvic compression on form closure, force closure, and neuromotor control of the lumbopelvic spine-a systematic review. Man Ther, 2012, 17: 275284. [Medline] [CrossRef]

9) Pel JJ, Spoor CW, Goossens RH, et al.: Biomechanical model study of pelvic belt influence on muscle and ligament forces. J Biomech, 2008, 41: 1878-1884. [Medline] [CrossRef]

10) Park KM, Kim SY, Oh DW: Effects of the pelvic compression belt on gluteus medius, quadratus lumborum, and lumbar multifidus activities during side-lying hip abduction. J Electromyogr Kinesiol, 2010, 20: 1141-1145. [Medline] [CrossRef]

11) Takasaki H, Iizawa $T$, Hall $T$, et al.: The influence of increasing sacroiliac joint force closure on the hip and lumbar spine extensor muscle firing pattern. Man Ther, 2009, 14: 484-489. [Medline] [CrossRef] 